\title{
Inverted Insertion (9)(q34.3q22.3q21.2) and Its Recombination Product: Duplication 9q21.2q22.3
}

To the Editor:

We read with interest a recent article in your journal by Dr. Narahara and his colleagues (1986) who described a kindred with two carriers of what they interpreted as an intrachromosomal direct shift, dir ins(9)(q34.3q22.1q31.3), and a now 9-yearold girl with a recombinant chromosome 9 . It was deduced that the rec(9) in the girl resulted from crossing over at one of two loops formed during meiosis $I$ in her carrier mother, and thus carried duplication of the $9 \mathrm{q} 22.1 \rightarrow \mathrm{q} 31.3$ segment. The ABO locus was assigned to $9 \mathrm{q} 31.3 \rightarrow$ qter in view of the fact that the girl was a recombinant for the locus.

We studied another kindred in which an apparently identical ins(9) chromosome is segregating through five generations. Our kindred and the maternal grandfather of the proband in Narahara's kindred both live in Tokuyama, a city with a 113,000 population. It is thus likely, but yet to be proven, that the two kindreds are related with each other.

Our interpretation of the ins(9) is different from Narahara's (Fig. 1, upper row). It involves insertion of an inverted $9 \mathrm{q} 21.2 \rightarrow \mathrm{q} 22.3$ segment into $9 \mathrm{q} 34.3$. Pairing of the inv ins(9) chromosome with a normal chromosome 9 during meiosis $I$ in a carrier individual would produce two loops, one involving the inverted q21.2 $\rightarrow$ $\mathrm{q} 22.3$ segment and the other the $\mathrm{q} 22.3 \rightarrow \mathrm{q} 34.3$ segment (Fig. 1, lower row). Odd numbers of crossing over in the latter loop would produce a recombinant chromosome with duplication of the $\mathrm{q} 21.2 \rightarrow \mathrm{q} 22.3$ segment and one with deficiency of the same segment (Fig. 2). Family studies in our kindred disclosed three ins $(9)$ carriers and two individuals with dup $9 \mathrm{q} 21.2 \rightarrow \mathrm{q} 22.3$ (Fig. 3). It was deduced that both 11-2 and 11-3, and also either I-1 or I-2, were carriers of the inv ins(9) chromosome. Thus, the trait was transmitted through at least five generations.

$\mathrm{V}-4$, the proband in our kindred, a 2 year 2 month-old girl with dup 9q21.2 $\rightarrow$ q22.3, weighed $1,874 \mathrm{~g}$ at birth. She walked at 15 months but did not speak meaningful words at age $22 / 12$ years. She measured $76.6 \mathrm{~cm}(-3.2 \mathrm{SD})$ and weighed $8 \mathrm{~kg}(-3 \mathrm{SD})$. She had ocular hypertelorism, a short nose with a depressed nasal tip, short neck, low-set, malformed ears, fifth finger clinodactyly, absence of bilateral palmar triradii $\mathrm{C}$ and distally placed axial triradii. Her bone age was correspondent to her chronological age. III-5, a maternal distant relative of the proband, also carries the dup(q) chromosome. She is now 45 years old and mentally retarded, but no other details are known to us. The proband in Narahara's kindred, a 5year-old girl with dup 9q, had a low birth weight, growth deficiency, ocular hypertelorism, and dermatoglyphic abnormalities. Her IQ was 92 and her bone age 


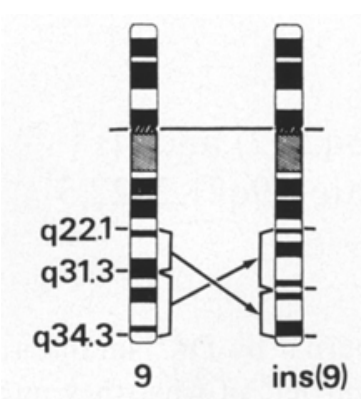

Direct Shift

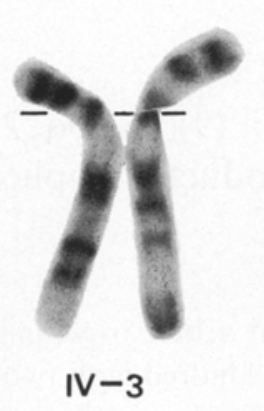

IV-3

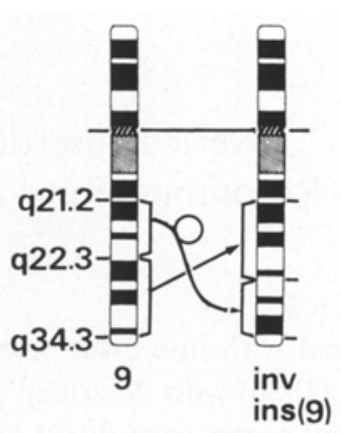

Inversion
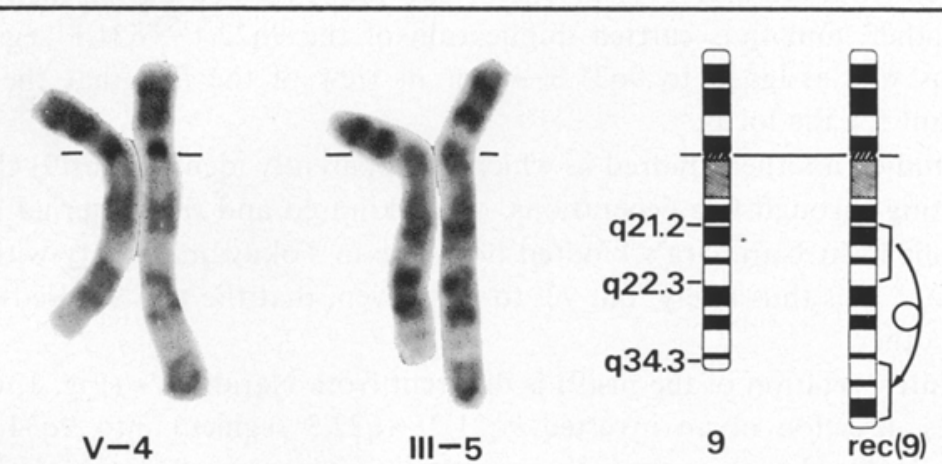

Fig. 1. Upper row: Left, interpretation of the ins(9) chromosome by Narahara et al. (1986), direct shift. Middle, chromosomes 9 in IV-3, the mother of the proband in our kindred, with inv ins(9) (q34.3q22.3q21.2). Right, our interpretation of the inv ins(9) chromosome. Lower row: Chromosomes 9 from $\mathrm{V}-4$, the proband, and III-5, her maternal distant relative, both with a recombinant chromosome 9 .

was retarded. In view of these findings a duplication of proximal $9 \mathrm{q}$ syndrome may be emerging. Its main features are: low birth weight, growth retardation, ocular hypertelorism, short nose, abnormal dermatoglyphics, and presence or absence of mental retardation.

Inversion insertion as observed in our kindred is apparently an extremely rare event. A recent French collaborative study on inversions in man listed 75 paracentric inversions in the world literature and 32 found in French cytogenetic laboratories (Groupe de Cytogénéticiens Français, 1986). The list included only two instances of paracentric inversion insertion: inv ins(1)(p31q32q31) reported by Palmer et al. (1977) and inv ins(3)(p25.5p21.1p13.5) described by Wyandt et al. (1980). Not included in the list were four kindreds in Newfoundland reported by Allerdice et al. (1983). Combined, these kindreds had 15 carriers of inv ins( 9 ) $(\mathrm{q} 22.1 \mathrm{q} 34.3 \mathrm{q} 34.1)$ and seven individuals with an unbalanced recombinant chromo- 

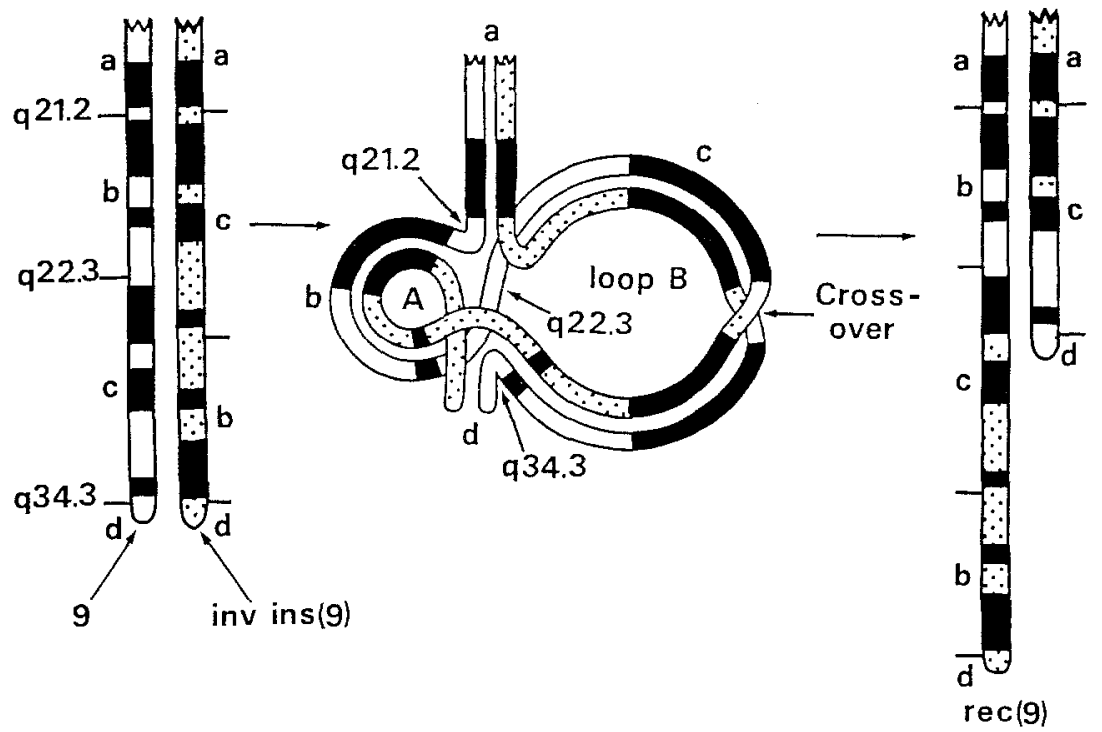

Fig. 2. Meiotic pairing and crossing over in an inv ins(9) carrier, resulting in recombinant chromosomes 9 , one with duplication and the other with deficiency of the $\mathrm{q} 21.2 \rightarrow$ q22.3 segment. Odd numbers of crossing over in loop $B$ would induce the recombinant chromosomes.

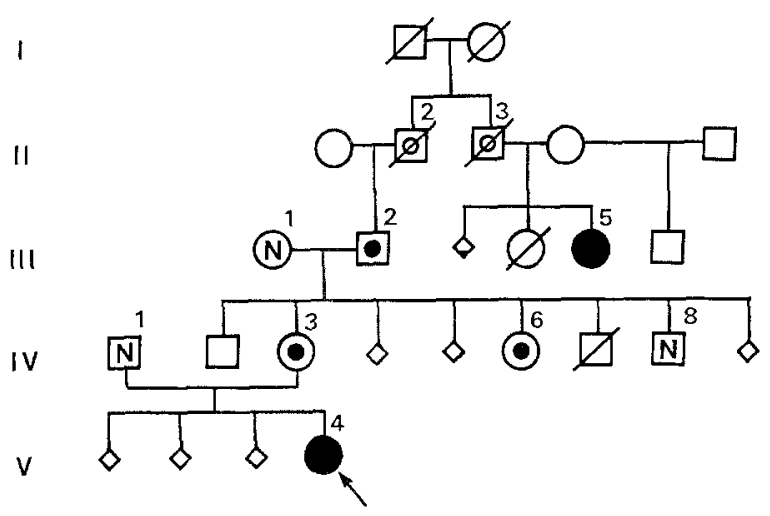
(N) N normalkaryotype
$\varnothing \varnothing$ dead
(อ invins (9)
$\diamond \quad$ spontaneous abortion
이 obligate carrier
$\diamond$
induced abortion
$\operatorname{rec}(9)$

Fig. 3. The pedigree of our kindred.

some 9 with duplication of the $9 \mathrm{q} 34.1 \rightarrow \mathrm{q} 34.3$ segment. No common ancestral couple has yet been identified. Thus the situation in these kindreds was analogous to that in Narahara's and our kindreds. In both, more than one kindred were 
ascertained close to one another. Both involved inverted insertion of a $9 \mathrm{q}$ segment: $9 \mathrm{q} 34.1 \rightarrow \mathrm{q} 34.3$ in Allderdice's kindreds and 9q21.2 $\rightarrow \mathrm{q} 22.3$ in Narahara's and our kindreds.

While the ABO locus was mapped to $9 \mathrm{q} 31.3 \rightarrow$ qter by Narahara et al. (1986), our interpretation of the ins(9) chromosome indicates that it is located at $9 \mathrm{q} 21.2 \rightarrow$ qter. The conclusion is not contradictory to a recent report that the $\mathrm{ABO}$ locus maps to $9 \mathrm{q} 22.1 \rightarrow \mathrm{q} 34.3$ (Allderdice et al., 1985).

\section{REFERENCES}

Allderdice, P.W., Eales, B., Onyett, H., Sprague, W., Henderson, K., Lefeuvre, P.A., and Pal, G. 1983. Duplication 9q34 syndrome. Am. J. Hum. Genet. 35: 1005-1019.

Allderdice, P.W., Kaita, H., Lewis, M., McAlpine, P.J., Wong, P., Anderson, J., and Giblett, E.R. 1986. Segregation of marker loci in families with an inherited paracentric insertion of chromosome 9. Am. J. Hum. Genet. 39: 612-617.

Groupe de Cytogénéticiens Français. 1986. Paracentric inversions in man. A French collaborative study. Ann. Génét. 29: 169-176.

Narahara, K., Takahashi, Y., Kikkawa, K., Wakita, Y., Kimura, S., and Kimoto, H. 1986. Assignment of $\mathrm{ABO}$ locus to $9 \mathrm{q} 31.3 \rightarrow$ qter by study of a family in which an intrachromosomal shift involving chromosome 9 is segregating. Jpn. J. Human Genet. 31: 289-296.

Palmer, C.G., Christian, J.C., and Merritt, A.D. 1977. Partial trisomy 1 due to a "shift" and probable location of the duffy $(F y)$ locus. Am. J. Hum. Genet. 29: 371-377.

Wyandt, H.E., Kasprzak, R., Ennis, J., Willson, K., Koh, U., Schnatterly, P., Wilson, W., and Kelly, T.E. 1980. Interstitial $3 p$ deletion in a child due to paternal paracentric insertion inversion. Am. J. Hum. Genet, 32: 731-735.

Tadashi KaJin, Shinya Matsuura, Ichiro Murano, and Akira Kuwano

Department of Pediatrics, Yamaguchi University School of Medicine, Ube 755, Japan

(Received December 27, 1986)

Jpn. J. Human Genet. 